University of Wollongong

Research Online

Partnerships, Proof and Practice - International

Nonprofit and Social Marketing Conference

Faculty of Arts, Social Sciences \& Humanities

2008 - Proceedings

$7-2008$

\title{
Not Just Any Volunteers: Segmenting the Market to Attract the High- Contributors
}

Melanie J. Randle

University of Wollongong, mrandle@uow.edu.au

Sara Dolnicar

University of Wollongong, s.dolnicar@uq.edu.au

Follow this and additional works at: https://ro.uow.edu.au/insm08

\section{Recommended Citation}

Randle, Melanie J. and Dolnicar, Sara, "Not Just Any Volunteers: Segmenting the Market to Attract the High-Contributors" (2008). Partnerships, Proof and Practice - International Nonprofit and Social Marketing Conference 2008 - Proceedings. 7.

https://ro.uow.edu.au/insm08/7

Research Online is the open access institutional repository for the University of Wollongong. For further information contact the UOW Library: research-pubs@uow.edu.au 


\title{
Not Just Any Volunteers: Segmenting the Market to Attract the High-Contributors
}

\author{
Abstract \\ Growing competition in the third sector has resulted in non-profit organisations making more \\ sophisticated use of marketing techniques to attract volunteers. Not only are organisations attempting to \\ attract more volunteers but increasingly the focus is shifting to attracting the right type of volunteers, or \\ those who will contribute the most hours. This study segments the volunteering market by number of \\ hours contributed in the past 12 months, and identifies significant differences between the characteristics \\ of high-contribution and low-contribution volunteers. High-contribution volunteers are found to (1) exhibit \\ distinctive socio-demographic characteristics; (2) have a greater number, and broader range, of \\ motivations for volunteering; and (3) initially get involved in volunteering in different ways to low- \\ contribution volunteers. Findings are important because they provide practitioners with a description of \\ those individuals most likely to contribute more hours which can be used to increasingly attract these \\ types of people, and subsequently reduce the amount spent continually attracting new volunteers.

\section{Publication Details} \\ This conference paper was originally published as Randle, M. and Dolnicar, S., Not Just Any Volunteers: \\ Segmenting the Market to Attract the High-Contributors, Partnerships, Proof and Practice - International \\ Nonprofit and Social Marketing Conference 2008, University of Wollongong, 15-16 July 2008.
}




\title{
Not Just Any Volunteers: Segmenting the Market to Attract the High-Contributors
}

\author{
Melanie Randle and Sara Dolnicar, University of Wollongong
}

\begin{abstract}
Growing competition in the third sector has resulted in non-profit organisations making more sophisticated use of marketing techniques to attract volunteers. Not only are organisations attempting to attract more volunteers but increasingly the focus is shifting to attracting the right type of volunteers, or those who will contribute the most hours. This study segments the volunteering market by number of hours contributed in the past 12 months, and identifies significant differences between the characteristics of high-contribution and low-contribution volunteers. High-contribution volunteers are found to (1) exhibit distinctive sociodemographic characteristics; (2) have a greater number, and broader range, of motivations for volunteering; and (3) initially get involved in volunteering in different ways to lowcontribution volunteers. Findings are important because they provide practitioners with a description of those individuals most likely to contribute more hours which can be used to increasingly attract these types of people, and subsequently reduce the amount spent continually attracting new volunteers.
\end{abstract}

\section{Introduction and Background}

In recent decades many countries around the world have experienced a dramatic expansion of the third sector. The increase in non-profit organisations has been attributed to a number of factors including the shift of responsibility for services previously provided by government to the third sector (Kingfisher, 2002). The growing number of social issues requiring support has also contributed, for example the growth in mortgage debt and resultant financial pressures on families, and the environmental related problems, such climate change, which have not yet emerged as high priorities on the agendas of many government bodies.

However, the increase in the number of third sector organisations has not been accompanied by an equal growth in the availability of human and financial resources. Therefore, in an effort to continue achieving their goals, non-profit organisations are taking a more pragmatic approach to their operation and using techniques and processes which have, until now, been more commonly seen in the for-profit sector. This has been the case in the field of marketing with traditional "commercial" concepts such as branding, positioning and targeting increasingly being applied within the non-profit sector (Chiagouris, 2005; Venable, Rose, Bush and Gilbert, 2005; Wray, 1994). However, one marketing technique which has been slow to be adopted in the non-profit arena is market segmentation. Market segmentation is the process by which a heterogeneous market is split into sub-groups which are homogenous in terms of one or a set of particular characteristics. To date, there have been limited attempts to segment the volunteering market (Dolnicar and Randle, 2007; Heidrich, 1990; Shelley and Polonsky, 2002), but with growing acknowledgement of the heterogeneous nature of the market, the value of segmentation as a way of more effectively targeting individuals likely to volunteer is increasingly being recognised. 
Increased competition has also resulted in many volunteering organisations considering not only the number of volunteers they attract but the type of volunteers they attract. Recruitment costs can be dramatically reduced if organisations can recruit volunteers who are prepared to contribute more time to the cause and stay for longer. These individuals are valuable because they become experienced in the particular role they are performing and reduce the advertising and training costs associated with attracting and inducting new volunteers. Currently, however, there is little information regarding who these high-contribution volunteers are and if and how they are different from individuals who volunteer less frequently. The purpose of this study is to identify whether high-contribution volunteers differ significantly from lowcontribution volunteers in their personal characteristics and motivations, and whether this information can be used to more effectively target high-contribution volunteers.

\section{Prior Research}

Many studies have attempted to identify and describe those individuals most likely to volunteer. Some have taken a sample of people who have performed a particular type of volunteer work, for example volunteering for the Girl Guides (Nichols and King, 1999) or the Red Cross (Frisch and Gerrard, 1981) and simply described their characteristics. Others have compared a sample of volunteers with a sample of non-volunteers to test for, and describe, significant differences (Dolnicar and Randle, 2006). However a limitation of most studies is that to form the segment of "volunteers" they group together everyone who has performed any volunteer work within a defined timeframe, say the past 12 months. This means that individuals who have volunteered only once for a few hours in the past year are grouped with those who have regularly contributed multiple hours every week during the past year. These studies fail to consider that there may be very different types of people who engage in lowversus high-frequency volunteering activities and that understanding these differences may make it easier for organisations to attract people who are likely to contribute more hours. This study addresses this gap by segmenting the volunteering market a priori based on the number of hours contributed by the individual in the past 12 months.

In terms of who is most likely to volunteer, the results of previous studies are conflicting. One factor which consistently emerges as a strong predictor of volunteering behaviour is education (McPherson and Rotolo, 1996; Reed and Selbee, 2000). However for other sociodemographic characteristics the profile of volunteers varies significantly from study to study. For example, Curtis, Grabb and Baer (1992) found volunteers most likely to be employed full-time, whereas Smith (1999) found volunteers more likely to work part-time. A study of Red Cross volunteers found women more likely to volunteer (Frisch and Gerrard, 1981), while studies of political volunteers find men more likely to be involved (Riecken, Babakus and Yavas, 1994). Considering that different segments of the volunteering market display such distinct characteristics it is expected that when segmented by volunteering contribution the resultant groups will also display distinctive characteristics. Therefore, it is hypothesised that:

\section{H1: High-contribution volunteers will be characterised by a distinct socio-demographic profile when compared to low-contribution volunteers.}

In terms of reasons why people volunteer, most researchers acknowledge that motivations are multifaceted (Bendapudi, Singh and Bendapudi, 1996; Omoto and Snyder, 1995). That is, people become involved because of a combination of altruistic reasons (e.g. to help those less fortunate) and egoistic reasons (e.g. enjoyment or to develop skills to help their career). 
However, what is not known is whether the number of reasons for involvement is different for different segments of the market. It seems likely that individuals who volunteer regularly and consistently over a long period are likely to be motivated by a greater number of reasons for involvement. For these people, if one of their reasons for volunteering reduces in importance the other reasons for involvement are enough to keep them actively volunteering. On the other hand, if low-contribution volunteers are motivated by fewer factors and one of these reduces in importance (e.g. if they volunteer for their child's school but the child leaves that school) they would have no other reason to continue and therefore stop volunteering for that cause. Therefore it is hypothesised that:

\section{H2: High-contribution volunteers cite a greater number of motivations for volunteering than low-contribution volunteers.}

\section{H3: High-contribution volunteers exhibit a broader range of motivations for volunteering than low-contribution volunteers.}

Numerous studies have investigated the attitudes or mindset that characterise volunteers. Findings include that volunteers display pro-social attitudes (Wymer, 1997) a strong sense of civic duty (Florin, Jones and Wandersman, 1986) and feel a personal responsibility to support the common good (Reed and Selbee, 2000). Accepting that volunteers do have distinctive attitudes which intrinsically motivate them to perform some form of social service, it is hypothesised that this would also influence the way they come to be involved in volunteering activities. That is, the more involved, higher-contribution, volunteers are more likely to have initiated involvement themselves (intrinsic motivation) rather than have been asked or persuaded by others (extrinsic motivation) to become involved. Therefore, it is hypothesised that:

\section{H4: High-contribution volunteers are more likely to actively seek out volunteering opportunities, whereas low-contribution volunteers are more likely to become involved because they were encouraged to do so by someone else.}

\section{Empirical Study}

The data for this study was collected during September-October 2006 in Australia using an online internet panel, which is set up and maintained such that it is representative of the population. Participants completed a 30 minute self-completion survey. To allow for hypothesis testing and profiling of segments, individuals answered questions relating to their past volunteering behaviour, reasons for volunteering and personal characteristics.

A total of 848 individuals indicated they had volunteered in the past 12 months. Segments were constructed according to the total number of hours volunteered in the past year. An extreme group design was employed (Alf and Abrahams, 1975), whereby high and low subgroups were isolated and the remaining mid-level group eliminated from analysis. Lowcontribution volunteers were defined as individuals who contributed between 1-19 hours in the past 12 months $(n=449)$ and high-contribution volunteers were defined as those who contributed 40 or more hours in the past 12 months $(n=271)$. Those in the mid-range, who had volunteered for between 20-39 hours $(n=128)$, were excluded. Therefore, the total sample size used for this analysis was 720 . Analysis of variance was used to test the significance of metric variables and Chi-squared tests were used to test the significance of nominal and ordinal variables. Unless otherwise specified, all statistics reported in this paper have significance levels of $95 \%$ or higher. 


\section{Results}

\section{H1: High-contribution volunteers will be characterised by a distinct socio-demographic profile when compared to low-contribution volunteers.}

No significant differences were found between the groups in relation to sex or income. Surprisingly, and inconsistent with other studies of volunteers, education also failed to discriminate between segments. Despite this, a number of significant differences were found between the groups. High-contribution volunteers had a significantly higher number of parttime employees (27\%) and non-working individuals (17\%) than the low-contribution group (14\% and $12 \%$ respectively), while low-contribution volunteers had the highest proportion of full-time employees ( $60 \%$, compared to $50 \%), \chi^{2}(4)=23.3, p=0.000$. Intuitively this seems logical because non-working and part-time employees would have more time to regularly devote hours to another cause, while the time restraints placed on full-time employees would be a barrier to frequent involvement. High-contribution volunteers were more likely to be older, with 33\% aged between 36-45 (compared to 18\%), and 27\% aged 46 or above (compared to 13\%). Conversely, low-contribution volunteers had a high proportion of younger individuals between 18-25 (31\% compared to 16\%) and 26-35 (37\% compared to $25 \%), \chi^{2}(5)=55.0, p=0.000$. In terms of relationship status, high-contribution volunteers were more likely to be married or living with a partner (62\% compared to 54\%) and lowcontribution volunteers were more likely single ( $43 \%$ compared to $29 \%), \chi^{2}(5)=15.6$, $p=0.008$. High-contribution volunteers were also more likely to have children (51\% compared to $38 \%$ ) while low-contribution were likely to be without children (62\% compared to $49 \%$ ), $\chi$ ${ }^{2}(1)=6.6, p=0.007$. That a number of significant socio-demographic differences were found between the high- and low-contribution volunteers means hypothesis H1cannot be rejected.

\section{H2: High-contribution volunteers cite a greater number of motivations for volunteering than low-contribution volunteers.}

Respondents were given a list of 19 possible reasons for volunteering, for example to help those less fortunate or to maintain services they may use one day. Respondents indicated which of the reasons applied to them by either ticking or leaving blank the box next to each reason. Participants could tick as many reasons as applied to them. The average number of reasons ticked by each group was calculated and ANOVA performed to assess the significance of differences. The average number of motivations applying to the lowcontribution group was 6.7 and the average for the high-contribution group was 9.0. This was significant at the $99.9 \%$ level $(\mathrm{F}=53.6, \mathrm{df}=1)$, therefore hypothesis $\mathrm{H} 2$ cannot be rejected.

\section{H3: High-contribution volunteers exhibit a broader range of motivations for volunteering than low-contribution volunteers.}

To test hypothesis H3 not only were the average number of reasons for volunteering considered but the types of reasons were investigated. Those reasons which applied to the majority of each segment (that is, the reasons which were ticked by over $50 \%$ of the segment) were analysed. In the low-contribution group, only four motivations applied to the majority. These were because "it gives me the chance to help others"; "I can give something back to society"; "it will improve my community"; and "I can support an important cause". These four reasons also applied to the majority of the high-contribution group, but an additional five reasons also applied to the majority of the high-contributors. These were because "I can meet different types of people"; "it sets a good example for others"; "I can socialise with people who are like me"; "it keeps me active”; and "I feel like I am doing a good job”. Interestingly, while the four reasons applying to the low-contribution group are all altruistic in nature, the high-contribution group nominated not only altruistic motivations for involvement, but a 
number of egoistic reasons that essentially provide benefits not only to others but also to themselves, such as being able to meet different types of people and keep active. This balance of helping others plus benefiting oneself is likely to be a key factor in the high-contribution group being willing to keep donating more hours for a longer period, because they feel as though they also have benefited personally in some way from their involvement. This is the fundamental concept of relationship marketing, that the relationship must be mutually beneficially for it to be healthy and lasting in the long term (Arnett, German and Hunt, 2003). That the majority of the high-contribution group indicated a wider range of altruistic and egoistic reasons for involvement means that hypothesis H3 cannot be rejected.

\section{H4: High-contribution volunteers are more likely to actively seek out volunteering opportunities, whereas low-contribution volunteers are more likely to become involved because they were encouraged to do so by someone else.}

Participants were asked to indicate how it was that they first became involved in volunteering by ticking one of five answer options. As expected, high-contribution volunteers had the highest proportion indicating they became involved after finding out about volunteering opportunities themselves (21\%), while low-contribution volunteers were more likely to indicate they became involved because someone asked them to be involved (27\%), $X^{2}(5)=19.8, p=0.001$. Therefore, hypothesis H4 cannot be rejected.

\section{Discussion and Future Research}

The distinctive socio-demographic characteristics of high-contribution volunteers provide insight as to who the people are who contribute the most hours volunteering. They are likely to be married or living with a partner, not working or in part-time employment, have children and be aged over 35 years old. That they are motivated by a range of altruistic and egoistic motivations means that a package of benefits not only to others and the community, but also to themselves, is the message that will be most meaningful and motivating for them. The fact that they are the group most likely to seek out information on volunteering opportunities themselves means that organisations need to make sure that information on their particular cause is readily available, clear and concise.

The present study has provided evidence to suggest that high-contribution volunteers are significantly different from low-contribution volunteers in terms of their socio-demographic characteristics, motivations for involvement and how they initially become involved in volunteering. The results of this study are important for managers of volunteering organisations because they allow them not only to identify those individuals who are likely to become involved in volunteering, but those who are likely to contribute the highest number of hours. This enables them to minimise the costs of advertising, recruitment and training which are associated with new volunteers. In the current environment of reduced funding and increased competition, it is fundamental that organisations make the most efficient use of their limited resources. Only by doing this can they continue to meet their organisational goals and provide important public services which would otherwise not be provided by government. This study provides a platform from which further research could be launched, for example investigations of the media usage and leisure time activities of high-contribution volunteers. This would contribute to building a fuller picture of this segment by providing insight as to not only the messages most likely to resonate with the group but also the media channels most likely to reach them. 


\section{References}

Alf, E. F., Abrahams, N. M., 1975. The Use of Extreme Groups in Assessing Relationships. Psychometrika 40(4), 563-572.

Arnett, D. B., German, S. D., Hunt, S. D., 2003. The Identity Salience Model of Relationship Marketing Success: The Case of Nonprofit Marketing. Journal of Marketing 67(2), 89-106.

Bendapudi, N., Singh, S. N., Bendapudi, V., 1996. Enhancing Helping Behavior: An Integrative Framework for Promotion Planning. Journal of Marketing 60(3), 33-49.

Chiagouris, L., 2005. Nonprofit Brands Come of Age. Marketing Management 14(5), 30-33.

Curtis, J. E., Grabb, E. G., Baer, D. E., 1992. Voluntary Association Membership in Fifteen Countries: A Comparative Analysis. American Sociological Review 57(2), 139-152.

Dolnicar, S., Randle, M. 2006. Environmental Volunteers: Are They Driven By Altruism and a Strong Feeling of Regional Identity? Australasian Nonprofit and Social Marketing (ANSM) Conference CD Proceedings. Newcastle, New South Wales.

Dolnicar, S., Randle, M., 2007. The International Volunteering Market: Market Segments and Competitive Relations. International Journal of Nonprofit and Voluntary Sector Marketing 12(4), 250-370.

Florin, P., Jones, E., Wandersman, A., 1986. Black Participation in Voluntary Associations. Journal of Voluntary Action Research 15(1), 65-86.

Frisch, M. B., Gerrard, M., 1981. Natural Helping Systems: A Survey of Red Cross Volunteers. American Journal of Community Psychology 9(5), 567-579.

Heidrich, K. W., 1990. Volunteers Life-Styles: Market Segmentation Based on Volunteers' Role Choices. Nonprofit and Voluntary Sector Quarterly 19(1), 21-31.

Kingfisher, C., 2002. Western Welfare in Decline: Globalisation and Women's Poverty, University of Pennsylvania Press, Philadelphia.

McPherson, J. M., Rotolo, T., 1996. Testing a Dynamic Model of Social Composition: Diversity and Change in Voluntary Groups. American Sociological Review 61(2), 179-202.

Nichols, G., King, L., 1999. Redefining the Recruitment Niche for the Guide Association in the United Kingdom. Leisure Sciences 21(4), 307-320.

Omoto, A. M., Snyder, M., 1995. Sustained Helping Without Obligation: Motivation, Longevity of Service, and Perceived Attitude Change Among AIDS Volunteers. Journal of Personality and Social Psychology 68(4), 671-686.

Reed, P. B., Selbee, L. K., 2000. Distinguishing Characteristics of Active Volunteers in Canada. Nonprofit and Voluntary Sector Quarterly 29(4), 571-592. 
Riecken, G., Babakus, E., Yavas, U., 1994. Facing Resource Attraction Challenges in the Nonprofit Sector: A Behavioristic Approach to Fund Raising and Volunteer Recruitment. Journal of Professional Services Marketing 11(1), 45-70.

Shelley, L., Polonsky, M. J., 2002. Do Charitable Causes Need to Segment Their Current Donor Base on Demographic Factors?: An Australian Examination. International Journal of Nonprofit and Voluntary Sector Marketing 7(1), 19-29.

Smith, J. D., 1999. Poor Marketing or the Decline of Altruism? Young People and Volunteering in the United Kingdom. International Journal of Nonprofit and Voluntary Sector Marketing 4(4), 372-377.

Venable, B. T., Rose, G. M., Bush, V. D., Gilbert, F. W., 2005. The Role of Brand Personality in Charitable Giving: An Assessment and Validation. Journal of the Academy of Marketing Science 33(3), 295-312.

Wray, B. R., 1994. Branding, Product Development and Positioning the Charity. The Journal of Brand Management 1(6), 363-370.

Wymer, W. W., 1997. Segmenting Volunteers Using Values, Self-Esteem, Empathy, and Facilitation as Determinant Variables. Journal of Nonprofit and Public Sector Marketing 5(2), 3-28. 